\title{
Correction to: Effects of a Brazilian cardioprotective diet and nuts on cardiometabolic parameters after myocardial infarction: study protocol for a randomized controlled clinical trial
}

\author{
Aline Marcadenti ${ }^{1,2 *}$, Bernardete Weber ${ }^{1}$, Angela Cristine Bersch-Ferreira ${ }^{1}$, Rachel Helena Vieira Machado ${ }^{1}$, \\ Camila Ragne Torreglosa', Enilda Maria de Sousa Lara, Lucas Ribeiro da Silva', Renato Hideo Nakagawa Santos ${ }^{1}$, \\ Debora Harumi Kodama Miyada', Erica Regina Ribeiro Sady ${ }^{1}$, Rosana Perim Costa', Leopoldo Piegas ${ }^{4}$, \\ Erlon Oliveira de Abreu-Silva ${ }^{1,4,5}$, Alexandre Schaan de Quadros², Camila Weschenfelder², \\ Júlia Lorenzon dos Santos², Gabriela Corrêa Souza ${ }^{6,7}$, Suena Medeiros Parahiba7 , Ana Paula Trussardi Fayh" \\ Danielle Soares Bezerra ${ }^{9}$, Ana Paula Perillo Ferreira Carvalho ${ }^{10}$, Malaine Morais Alves Machado ${ }^{10}$, \\ Sandra Mary Lima Vasconcelos ${ }^{11}$, Jéssika Araújo ${ }^{11}$, José Albuquerque de Figueiredo Neto ${ }^{12}$, \\ Luciana Pereira Pinto Diass ${ }^{12}$, Francisca Eugenia Zaina Nagano ${ }^{13}$, Cássia Cristina Paes de Almeida ${ }^{14}$, \\ Annie Seixas Bello Moreira ${ }^{15}$, Débora Pinto Gapanowicz ${ }^{15}$, Eduardo Purgatto ${ }^{16}$, Marcelo Macedo Rogero ${ }^{17}$, \\ Geni Rodrigues Sampaio ${ }^{17}$, Elizabeth Aparecida Ferraz da Silva Torres ${ }^{17}$, Graziela Biude Silva Duarte ${ }^{18}$ and \\ Alexandre Biasi Cavalcanti ${ }^{1}$
}

Correction to: Trials 22, $582(2021)$

https://doi.org/10.1186/s13063-021-05494-0

Following the publication of the original article [1], we were notified that Tables 3 and 4 were identical.

Originally, Table 3 was published as a copy of Table 4 . This has now been corrected.

Table 4 remains unchanged.

The original article has been corrected.

The original article can be found online at https://doi.org/10.1186/s13063 021-05494-0.

* Correspondence: amarcaden@hcor.com.br

${ }^{1} \mathrm{HCor}$ Research Institute (IP-HCor), Hospital do Coração (HCor), Abílio Soares Street, 250, 12th floor, São Paulo, SP Zip Code 04004-050, Brazil

${ }^{2}$ Graduate Program in Health Sciences (Cardiology), Instituto de Cardiologia/ Fundação Universitária de Cardiologia (IC/FUC), Porto Alegre, Rio Grande do Sul, Brazil

Full list of author information is available at the end of the article

\section{Author details}

${ }^{1}$ HCor Research Institute (IP-HCor), Hospital do Coração (HCor), Abílio Soares Street, 250, 12th floor, São Paulo, SP Zip Code 04004-050, Brazil. ${ }^{2}$ Graduate Program in Health Sciences (Cardiology), Instituto de Cardiologia/Fundação Universitária de Cardiologia (IC/FUC), Porto Alegre, Rio Grande do Sul, Brazil. ${ }^{3}$ Health Knowledge Implementation Laboratory (LICS), Hospital do Coração (HCor), São Paulo, São Paulo, Brazil. ${ }^{4}$ Division of Cardiology, Hospital do Coração (HCor), São Paulo, São Paulo, Brazil. ${ }^{5}$ Hemodynamics Service, Hospital do Servidor Público Estadual (HSPE), São Paulo, São Paulo, Brazil. ${ }^{6}$ Division of Nutrition, Hospital de Clínicas de Porto Alegre (HCPA), Porto Alegre, Rio Grande do Sul, Brazil. ${ }^{7}$ Post-Graduation Program in Food, Nutrition and Health, School of Medicine, Universidade Federal do Rio Grande do Sul (UFRGS), Porto Alegre, Rio Grande do Sul, Brazil. ${ }^{8}$ Department of Nutrition, Universidade Federal do Rio Grande do Norte (UFRN), Natal, Rio Grande do Norte, Brazil. ${ }^{9}$ Faculty of Health Science of Trairi, Universidade Federal do Rio Grande do Norte (FACISA-UFRN), Santa Cruz, Rio Grande do Norte, Brazil. ${ }^{10}$ Clinical Nutrition Unit, Hospital de Clínicas, Universidade Federal de Goiás (HC-UFG/EBSERH), Goiânia, Goiás, Brazil. ${ }^{11}$ Faculty of Nutrition, Universidade Federal de Alagoas (UFAL), Maceió, Alagoas, Brazil. ${ }^{12}$ Department of Cardiology, Universidade Federal do Maranhão (UFMA), São Luiz, Maranhão, Brazil. ${ }^{13}$ Complexo Hospital de Clínicas da Universidade

C The Author(s). 2021 Open Access This article is licensed under a Creative Commons Attribution 4.0 International License, which permits use, sharing, adaptation, distribution and reproduction in any medium or format, as long as you give appropriate credit to the original author(s) and the source, provide a link to the Creative Commons licence, and indicate if changes were made. The images or other third party material in this article are included in the article's Creative Commons licence, unless indicated otherwise in a credit line to the material. If material is not included in the article's Creative Commons licence and your intended use is not permitted by statutory regulation or exceeds the permitted use, you will need to obtain permission directly from the copyright holder. To view a copy of this licence, visit http://creativecommons.org/licenses/by/4.0/ The Creative Commons Public Domain Dedication waiver (http://creativecommons.org/publicdomain/zero/1.0/) applies to the data made available in this article, unless otherwise stated in a credit line to the data. 
Federal do Paraná (HC-UFPR), Curitiba, Paraná, Brazil. ${ }^{14}$ Universidade Federal do Paraná (UFPR), Curitiba, Paraná, Brazil. ${ }^{15}$ Instituto Nacional de Cardiologia (INC), Rio de Janeiro, Rio de Janeiro, Brazil. ${ }^{16}$ Department of Food Science and Experimental Nutrition/Food Research Center, Faculty of Pharmaceutical Sciences, Universidade de São Paulo (USP), São Paulo, São Paulo, Brazil.

${ }^{17}$ Department of Nutrition, School of Public Health, Universidade de São Paulo (USP), São Paulo, São Paulo, Brazil. ${ }^{18}$ Department of Food Science and Experimental Nutrition, Faculty of Pharmaceutical Science, Universidade de São Paulo (USP), São Paulo, São Paulo, Brazil.

\section{Published online: 29 September 2021}

\section{Reference}

1. Marcadenti, et al. Effects of a Brazilian cardioprotective diet and nuts on cardiometabolic parameters after myocardial infarction: study protocol for a randomized controlled clinical trial. Trials. 2021;22:582. https://doi.org/10.11 86/s13063-021-05494-0. 